\title{
Pocas señales de recuperación en el mercado laboral
}

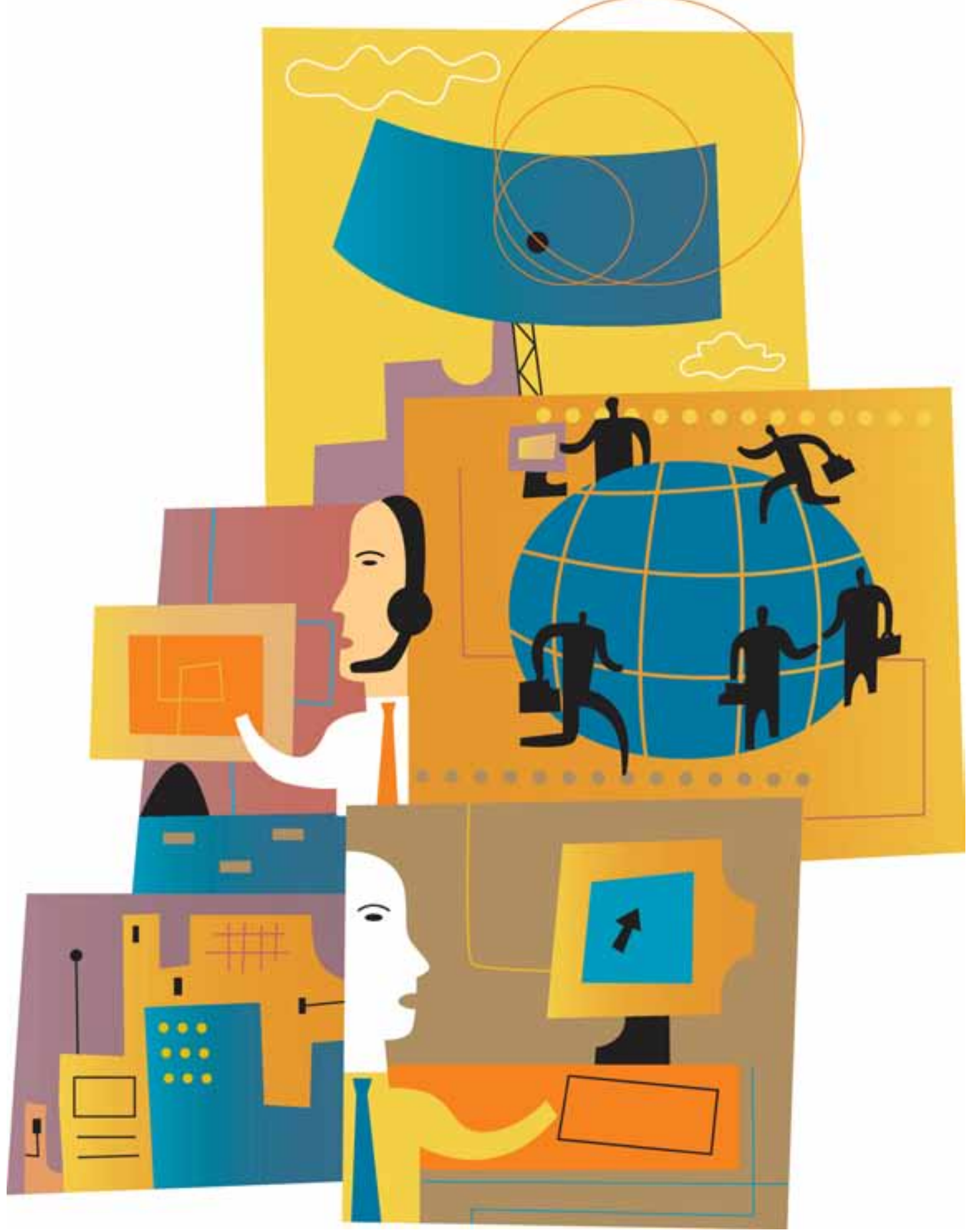

Hacia finales del 2013 comenzó a notarse una desaceleración de la economía. Un intodo el año 2014 fue la tasa de desempleo que hasta el trimestre móvil junio-agosto de sin embargo, en septiembre somienza caer de manera sostenida para hombres mujeres, llegando a $6.1 \%$ en la última medición disponible (octubre-noviembre 2014). Esta leve caida (en su peak del 2014 dich tasa llega a 6.7\%) no es sólo estacionalidad, sno que se mantiene al eliminar ese efecto (ver Gráfico 1).

A partir de los numeros, todavia no queda claro por qué tanto pesimismo en un contexto en el que las estadisticas de desempleo (aunque creciendo levemente) se mantienen muy por debajo de los niveles historicos. La clave podila estar en los cambios en la com-

Sor más importantesempleo es el indicaportamiento ciclico del mercado el comun indicador imperfecto para analizar la dinámica del mercado laboral. Al ser una medida estática, esconde los flujos de entrad y salida al desempleo. Para tener una vision más completa de lo que está ocurriendo en materia laboral es importante analizar dchos flujos.

Las tasas de creación y destrucción de trabajos pueden medirse directamente usand flujos brutos de personas que transitan Sin en ere Sin embargo, para hacer un seguimiento datos que sigan a las personas a travis de tiempo, los cuales no están disporibles con frecuencia interanual. Por esto se usa un minada por el empleo independiente (ver enfoque indirecto' que aproxima las tasas a Gráfico 3). El empleo por cuenta propia tien le la Nuev en

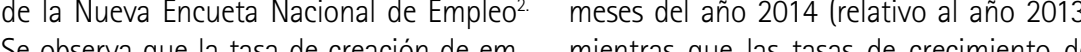
pleo también ha aumentado en los últimos mos trimestres móviles, revirtiendo la sistemáti- del 07-12\% con respecto a año anterior. ca baja que había experimentado desde el Más aún, tanto dentro del empleo asala trimestre febrero-abril del año 2014. La tasa riado como dentro del empleo por cuenta de destrucción de empleo, en tanto, no cede propia, el 2014 fue un año muy malo para pero termina siendo dominada por la tasa trabajadores de baja calificación. El crecide creación y es por esto que la tasa de des- miento se concentró en trabajadores que empleo comienza a disminuir (ver Grafico tienen enseñanza media o más. El nivel de 2). Este mismo comportamiento muestran empleo para los grupos menos educados las tasas de creación y destrucción laboral presenta tasas de crecimiento negativas por genero. dores agregados son consistentes con un leve repunte en el nivel de actividad económica (medido por el lmacec) en las ulti2014. Pero parecen no estar a tono con las expectativas de crecimiento recabadas por el Banco Central en su encuesta mensual, en la que el crecimiento esperado para el año 2015 baja de 4\% en la encuesta de enero 2014 a $26 \%$ en la encuesta de diciembre del mismo año.

Si bien las tasas de empleo global no fundamentan un ambiente de pesimismo, la composición del empleo cambia de modo preocupante.

Cuando se evalua el comportamiento empleo separando asalariados y cuenta propia se constata un cambio composicioen diente aumentan, es claro que la tendencia al alza en el nivel de empleo total está do-

to para empleo asalariado como para (t) el crecimiento de los contratos indefindos tiende a desacelerarse en el tiempo en anto que el empleo temporal o contingente mostrado tasas positivas los últimos dos mostres móviles (ver Gráfico 5 ).

2014 también se evidencia una caida sustancial en las horas de trabajo, lo que podria explicar que no hubiera habido un ajuste más fuerte en la tasa de empleo

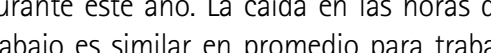
abajo es similar en promedio para trabadores asalariados y cuenta propia, pero 政 calificacion. Entre los trabajadores incententes, todos los grupos excepto mentandos in tecricos completos, experi-

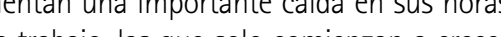
nuevamente hacia fines del año Los traba-

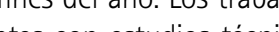
cos completos, por el contrario, aumentan de manera sostenida sus horas de trabajo. 
Entre los trabajadores asalariados, el grupo empleo mostró un crecimiento de 2.4\% en En resumen, la mejora que parece expecon estudios universitarios es el que regis- doce meses, siendo el empleo cuenta propia rimentar el nivel de empleo en el mercado tra reducciones menos importantes en sus la categoria ocupacional que más creció en laboral esconde importantes desequilhoras de trabajo, incluso repuntando en los doce meses (11.2\%). Por el contrario, el em- brios, entre tipos de empleo (asalariado últimos meses del año. son

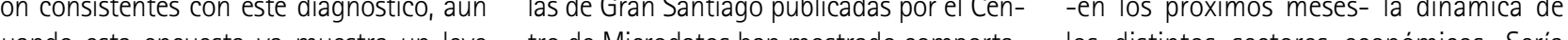
a me periodo de año Sesin la ultima medi- espros que las cifras na del 2014, es de

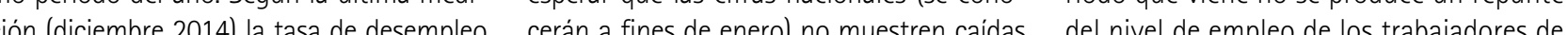

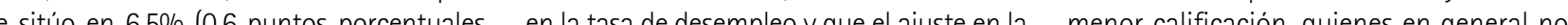

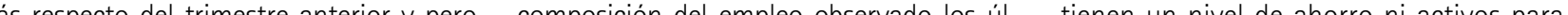

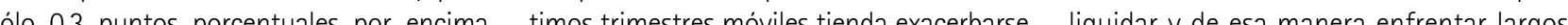
de igual periodo de 2013). Por su parte, el aún más.
Gráfico 1. Evolución de la tasa de desempleo.

Tasa de Desempleo

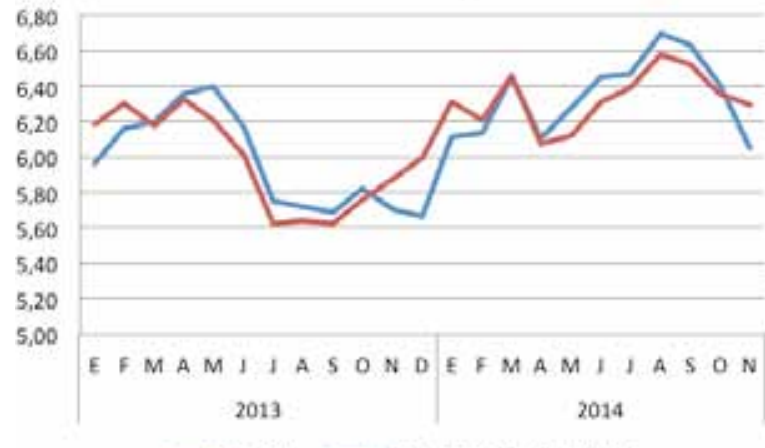

Fuente: Nueva Encuesta Nacional de Empleo del INE

Gráfico 3. Tasa de crecimiento en el empleo por categoria

ocupacional (Tasa de Crecimiento en 12 Meses)

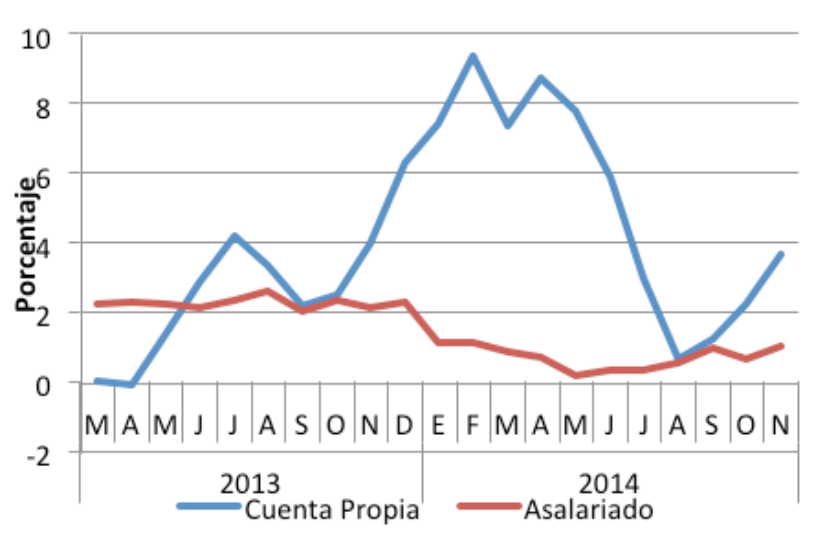

Fuente: Elaboración propia usando I a Nueva Encuesta Nacional de Empleo del INE
Gráfico 2. Tasas de Creación y Destrucción de Trabajo.

\section{Tasas de Creación y Destrucción de Trabajo}

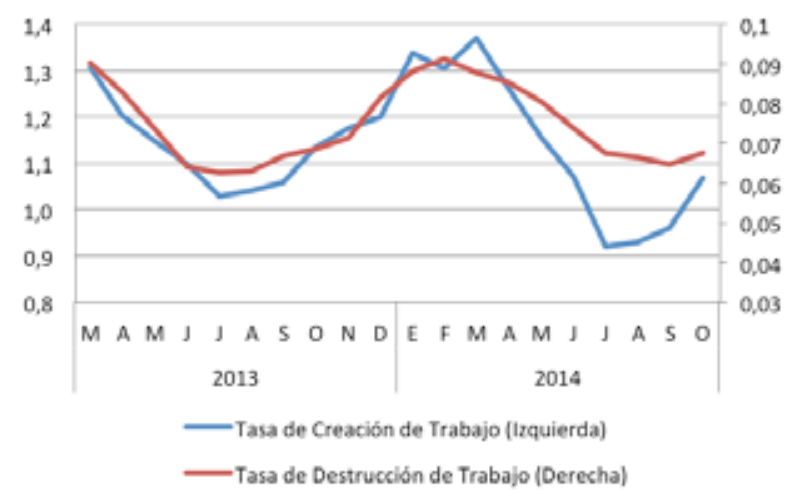

—Tasa de Destrucción de Trabajo (Derecha)

Gráfico 4. Empleo Asalariado y Cuenta Propia por Nivel de Escolaridad (Tasa de Crecimiento en 12 Meses)

A. Asalariados

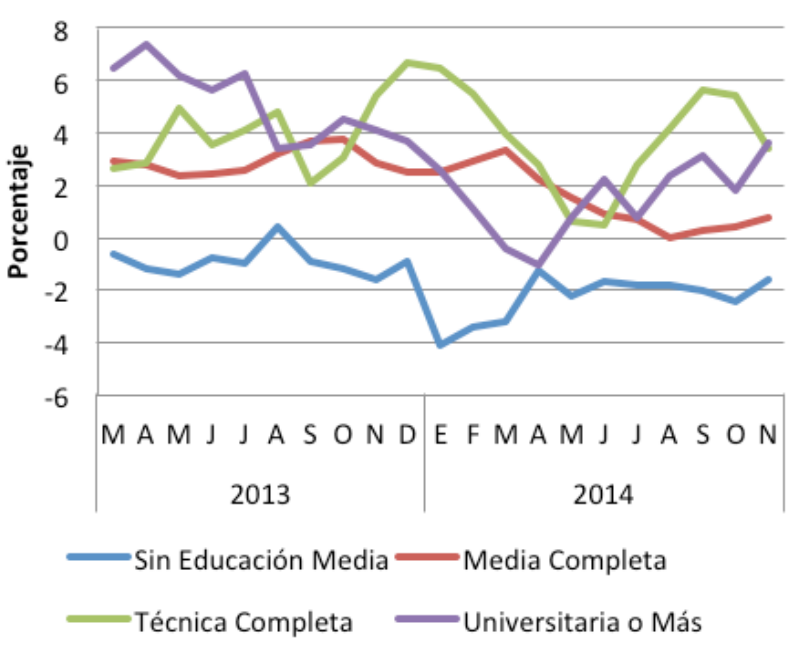

Fuente: Nueva Encuesta Nacional de Empleo del INE

Gráfico 5. Empleo Asalariado por Tipo de Contrato Tasa de Crecimiento en 12 Meses)

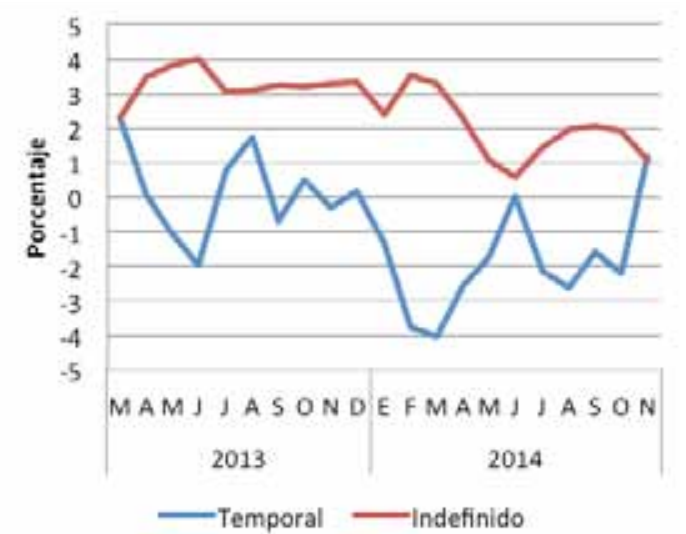

Fuente: Nueva Encuesta Nacional de Empleo del INE

Para más detalles ver: Robert Shimer

. Además, se supone que todos los trabajadores tienen la misma probabilidad de encontrar trabajo en el trimestre-movil correspondiente. La tasa a la cual se destruyen trabajos, por su parte, se estima (aproxima) que dejan de serlo (dada la tasa de creación estimada) sea consistente con el número de desempleados observado en el periodo inmediatamente futuro.
B. Cuenta Propia

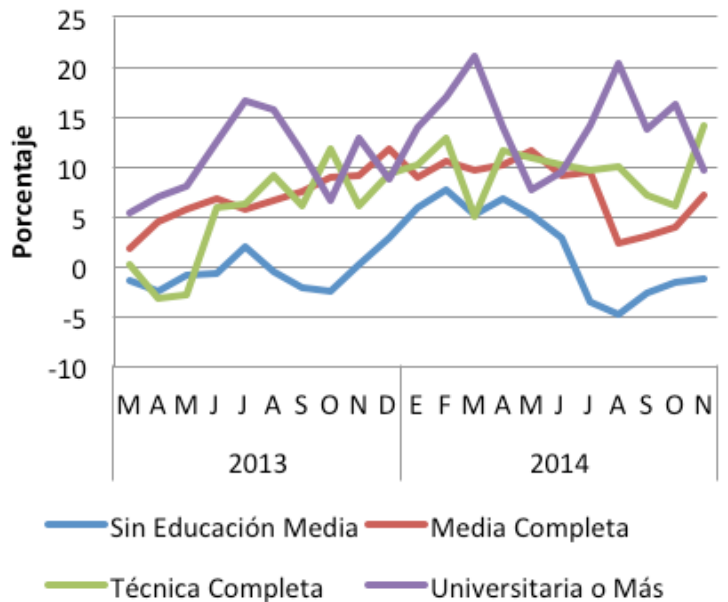

Fuente: Nueva Encuesta Nacional de Empleo del INE 